\title{
Propriedades físicas do solo e produtividade de arroz irrigado por inundação no sistema plantio direto
}

\author{
Janete Denardi Munareto(1), Amauri Nelson Beutler(1), Cleiton José Ramão(1), Naimã Pinto Dias ${ }^{(1)}$, \\ Priscila Vogelei Ramos(1), Bruna Canabarro Pozzebon(1), Cleber Maus Alberto(1) e Gustavo Cantori Hernandes ${ }^{(2)}$ \\ (1)Universidade Federal do Pampa, Campus Itaqui, Luiz Joaquim de Sá Britto, s/no, CEP 97650-000 Itaqui, RS. \\ E-mail: jdmunareto@gmail.com, amaurib@yahoo.com.br, cleitonramao80@hotmail.com, nayma_sanchotene@hotmail.com, \\ pv-ramos89@hotmail.com, bru_pozzebon07@hotmail.com, cleberalb@gmail.com ${ }^{(2)}$ Instituto Rio Grandense do Arroz, Rua Doutor Maia, \\ oㅜ 3698, Centro, CEP 97500-000 Uruguaiana, RS. E-mail: gustavo-hernandes@irga.rs.gov.br
}

Resumo - O objetivo deste trabalho foi avaliar as propriedades físicas do solo e a produtividade de arroz irrigado por inundação no sistema plantio direto, na fronteira oeste do Rio Grande do Sul, em comparação ao sistema convencional. Utilizou-se o delineamento experimental inteiramente casualizado, com três experimentos e dez repetições: E1, sistema plantio direto após nivelamento do terreno (E1PDR) e sistema convencional com duas gradagens a 0,0-0,07 m após nivelamento do terreno (E1C), sete anos de pousio do cultivo de arroz, com semeadura de azevém no inverno e pastejo animal; E2, sistema plantio direto (E2PD) e sistema convencional (E2C), após campo nativo; E3, sistema plantio direto (E3PD), sistema plantio direto após nivelamento do terreno com remaplan (E3PDR) e sistema convencional (E3C), após arroz irrigado em sistema convencional, durante um ano sob campo nativo. As propriedades físicas do solo diferiram pouco entre os sistemas de plantio direto e o sistema convencional. O cultivo continuado com arroz irrigado causou compactação do solo na camada $0,07-0,10 \mathrm{~m}$. A produtividade de arroz não diferiu nos sistemas plantio direto e convencional, nos experimentos 1 e 2 . No experimento 3, com maior quantidade de restos culturais de arroz, a produtividade foi superior no sistema convencional.

Termos para indexação: Oryza sativa, manejo do solo, qualidade física do solo, rendimento.

\section{Soil physical properties and yield of flooded rice under no-tillage}

\begin{abstract}
The objective of this work was to evaluate the soil physical properties and the yield of flooded rice under no-tillage, in the west border of Rio Grande do Sul, Brazil, compared with the conventional tillage system. The experimental design was completely randomized, with three experiments (E) and ten replicates: E1, no-tillage after leveling (E1PDR) and conventional tillage with two harrowings at $0.0-0.07 \mathrm{~m}$ layer after leveling (E1C), after seven years of fallow of rice tillage, with sowing of rye grass in winter and grazing; E2, no-tillage (E2PD) and conventional tillage (E2C), after native field; E3, no-tillage (E3PD), no-tillage after leveling (E3PDR), and conventional tillage (E3C) after rice under conventional tillage, during one year under native field. The soil physical properties differed little between the no-tillage system and conventional tillage. Continued tillage with irrigated rice caused soil compaction in the $0.07-0.10 \mathrm{~m}$ layers. The rice yield did not differ between the no-tillage system and conventional tillage, in the experiments 1 and 2 . In experiment 3 , with greater amount of remaining rice straw, the yield was greater in the conventional tillage system.
\end{abstract}

Index terms: Oryza sativa, soil tillage, soil physical quality, yield.

\section{Introdução}

O Estado do Rio Grande do Sul produz mais de $50 \%$ do arroz do país, notadamente o arroz irrigado, que tem elevada produtividade, comparada ao arroz de terras altas (Sociedade Sul-Brasileira de Arroz Irrigado, 2010). O Município de Uruguaiana é o maior produtor nacional de arroz irrigado, seguido pelo Município de Itaqui, ambos fazem parte do bioma Pampa, com características peculiares de clima, solo e recursos hídricos. A economia da região é quase exclusivamente dependente das cadeias produtivas do arroz irrigado por inundação e da pecuária extensiva, fundamentalmente o setor primário.

Em relação ao clima, na região da Campanha e na fronteira oeste do Rio Grande do Sul, as estiagens que ocorrem nos primeiros meses do ano inviabilizam o cultivo de culturas anuais sem irrigação, como soja e milho, fator que é decisivo na utilização do solo, principalmente com arroz irrigado, pastagens de inverno e perenes destinadas à pecuária. 
O cultivo de arroz irrigado é realizado preferencialmente em solos com relevo plano a suave-ondulado que ocorrem em baixadas, geralmente mal drenados, chamados solos de várzeas, em razão da facilidade de manejo da irrigação por inundação para a cultura. Esses solos ocorrem nas diversas regiões do Brasil e, no Rio Grande do Sul correspondem a aproximadamente $25 \%$ da área total do estado (Pereira et al., 2005). No Município de Itaqui, ocorrem principalmente os Luvissolos, Plintossolos e Chernossolos. No Município de Uruguaiana, ocorrem os Chernossolos e, em maiores quantidades, os Neossolos Regolíticos (Streck et al., 2008), que são utilizados intensamente no cultivo de arroz irrigado.

O cultivo de arroz irrigado, no Rio Grande do Sul, com destaque para a região da Campanha e fronteira oeste, ainda é realizado, em grande parte, por vários anos seguidos, com o sistema convencional de preparo do solo, o que muitas vezes deixa as áreas em pousio no inverno. Porém, o cultivo de arroz sempre na mesma área causa aumento na infestação de plantas daninhas, principalmente a de arroz-vermelho. Associada a isso, a utilização de máquinas e implementos pesados, sucessivamente, degrada a estrutura do solo e causa a compactação subsuperficial, o que dificulta ainda mais o movimento de ar e água no solo (Pauleto et al., 1993).

O sistema plantio direto (PD), além de minimizar o problema do arroz-vermelho, tem proporcionado outros benefícios à orizicultura. No atual sistema de plantio direto, o preparo do solo é realizado logo após a colheita do arroz, nos meses de janeiro a março, e normalmente, compreende uma aração, duas gradagens e nivelamento com uma plaina niveladora, seguido do entaipamento (Pereira et al., 2005). O preparo antecipado do solo é feito para receber as sementes de arroz e, principalmente, estimular a germinação e a emergência de sementes de plantas daninhas, como as de arroz-vermelho e preto, num período em que estas não possam concorrer com a cultura do arroz (Pereira et al., 2005). Antes da semeadura é realizada apenas a dessecação das plantas invasoras. Portanto, caracteriza-se como um sistema semi-direto, visto que é feito revolvimento anual do solo, exceto antes da semeadura do arroz.

Quando o arroz irrigado é cultivado no sistema plantio direto, em rotação com culturas como o milho e a soja, prática já utilizada em algumas áreas de várzea do Rio Grande do Sul, o preparo do solo é dispensado, opção pouco viável na região da Campanha e fronteira oeste, em razão das estiagens.

No sistema de plantio direto, após o preparo do solo, é aconselhável a implantação de uma forrageira de inverno, e o azevém é a mais utilizada. Outras espécies, como aveia-preta, trevo-persa, trevo-branco e lotus (Lotus subbiflorus Lag.) cultivar El rincón têm apresentado desempenho promissor. Quando não houver interesse ou possibilidade de uma exploração mais racional da pecuária, a cobertura vegetal poderá ser composta pelas plantas que se estabelecerem naturalmente após o preparo do solo. Em solos de várzea, 2 a $3 \mathrm{Mg} \mathrm{ha}^{-1}$ de massa de matéria seca são suficientes, para que se tenha uma cobertura adequada para implantação do plantio direto. Quantidades maiores, além de dificultar a evaporação da água do solo, podem produzir ácidos orgânicos em níveis tóxicos ao arroz (Pereira et al., 2005).

Em solos de várzea com a utilização do sistema plantio direto de arroz irrigado e rotação com culturas anuais, Pedroti et al. (2001) relataram que ocorreu menor compactação (densidade do solo), em comparação ao cultivo contínuo de arroz em sistema de preparo convencional. Andres et al. (2001) verificaram que a rotação com culturas anuais proporcionou redução no banco de sementes de arroz-vermelho, que é considerada a principal invasora em lavouras de arroz irrigado.

A hipótese deste trabalho é de que o sistema plantio direto proporciona melhor qualidade física do solo e produtividade de arroz irrigado semelhante em comparação ao sistema de preparo convencional e semi-direto com revolvimento anual do solo.

O objetivo deste trabalho foi avaliar propriedades físicas do solo e a produtividade de arroz irrigado por inundação, no sistema plantio direto em comparação ao sistema convencional e semi-direto.

\section{Material e Métodos}

Os experimentos foram realizados em área situada a $29^{\circ} 40^{\prime} 55^{\prime \prime} \mathrm{S}$ e $56^{\circ} 38^{\prime} 17^{\prime \prime} \mathrm{W}$, e altitude de $85 \mathrm{~m}$, na fronteira oeste do Rio Grande do Sul, em um Neossolo Regolítico eutrófico (Santos et al., 2006). O clima é do tipo Cfa, segundo Köppen-Geiger.

Utilizou-se o delineamento experimental inteiramente casualizado, com três experimentos e dez repetições (parcelas de $3 \times 2 \mathrm{~m}$ ), com os seguintes 
tratamentos de manejo do solo: Experimento 1 (E1), sistema plantio direto após nivelamento do terreno com plaina niveladora remaplan NSI 10 (Indumec Indústria Mecânica Ltda., Curitiba, PR, Brasil) (E1PDR), e sistema convencional com duas gradagens a 0,0-0,07 $\mathrm{m}$ com nivelamento do terreno com plaina niveladora remaplan (E1C), após sete anos de pousio do cultivo de arroz e, com semeadura de azevém no inverno e pastejo animal o ano todo; Experimento 2 (E2), sistema plantio direto (E2PD) e sistema convencional (E2C), após campo nativo; Experimento 3 (E3), sistema plantio direto (E3PD), sistema plantio direto após passagem de plaina remaplan (E3PDR), e sistema convencional (E3C) após cultivo do arroz irrigado em sistema convencional, durante um ano em área de campo nativo. A lotação animal nas áreas, na época em que o arroz não foi cultivado, foi inferior a 1,2 unidade animal por hectare.

A composição granulométrica do solo, na camada 0,0-0,20 $\mathrm{m}$ de profundidade, determinada pelo método da pipeta (Claessen, 1997), foi: 215, 605 e $180 \mathrm{~g} \mathrm{~kg}^{-1}$ no E1; 265, 552 e $183 \mathrm{~g} \mathrm{~kg}^{-1}$ no E2; e 293, 510 e $197 \mathrm{~g} \mathrm{~kg}^{-1}$ de argila, silte e areia, respectivamente, no E3.

A caracterização química do solo na entrelinha, na camada $0,0-0,10 \mathrm{~m}$, realizada logo após a semeadura, e a massa de matéria seca na superfície do solo, determinada em área de $0,25 \mathrm{~m}^{2}$ antes da semeadura, estão apresentadas na Tabela 1.

Em agosto, foram aplicados herbicidas a todos os tratamentos, foi preparado o solo nos tratamentos em sistema convencional e nivelado o terreno. Ainda foram construídas e remontadas as taipas no sistema plantio direto, com camalhão de $0,12 \mathrm{~m}$ de altura e dimensionamento entre taipas suficiente para permitir uma lâmina de água de $\pm 0,04 \mathrm{~m}$ de altura sobre o solo, a qual foi aplicada 30 dias após a semeadura do arroz.

A semeadura foi realizada no mês de setembro no E2 e E3 e em dezembro no E1. As variedades Irga 424 (E2 e E3) e Puitá Inta CL (E1) foram semeadas na densidade de 60 sementes por metro e no espaçamento de $0,17 \mathrm{~m}$ entre linhas. A adubação foi de $240 \mathrm{~kg} \mathrm{ha}^{-1}$ de 09-23-30 de N-P-K, na semeadura; $160 \mathrm{~kg} \mathrm{ha}^{-1}$ de 30-00-20 N-P-K, 20 dias após a emergência; e $60 \mathrm{~kg} \mathrm{ha}^{-1}$ de 45-00-00 de N-P-K, na diferenciação do primórdio floral, aos 65 dias após a emergência, conforme recomendação da Sociedade Brasileira de Ciência do Solo (2004).

A estabilidade de agregados foi determinada em amostras indeformadas, coletadas na camada de 0,0-0,05 m, segundo Claessen (1997), com duas repetições, com uso de peneiras de 2,00, 1,00, 0,50, 0,25 e $0,105 \mathrm{~mm}$ de abertura de malha, e os resultados foram expressos pelo diâmetro médio geométrico (DMG). Para determinação da densidade do solo (Ds), porosidade total, macro e microporosidade, foram coletadas amostras indeformadas com cilindros de $0,05 \mathrm{~m}$ de diâmetro e $0,03 \mathrm{~m}$ de altura, nas camadas de $0,0-0,05$ e de $0,07-0,10 \mathrm{~m}$, determinadas segundo Claessen (1997).

Tabela 1. Caracterização química - pH, matéria orgânica (MO), Ca, Mg, K, P, saturação por bases (V\%) - e massa de matéria seca (MS) na superfície do solo antes da semeadura, em três experimentos e sistemas de manejo do solo para arroz irrigado ${ }^{(1)}$.

\begin{tabular}{|c|c|c|c|c|c|c|c|c|}
\hline Tratamento & $\begin{array}{c}\mathrm{pH} \\
\text { em } \mathrm{H}_{2} \mathrm{O}\end{array}$ & $\begin{array}{l}\text { MO } \\
(\%)\end{array}$ & $\begin{array}{c}\mathrm{Ca} \\
----\end{array}$ & $\begin{array}{l}\mathrm{Mg} \\
\mathrm{ol}_{\mathrm{c}} \mathrm{dn}\end{array}$ & K & $\begin{array}{r}\text { P-Mehlich } \\
\left(\mathrm{mg} \mathrm{dm}^{-3}\right)\end{array}$ & $\begin{array}{l}\mathrm{V} \\
(\%)\end{array}$ & $\begin{array}{c}\mathrm{MS} \\
\left(\mathrm{kg} \mathrm{ha}^{-1}\right)\end{array}$ \\
\hline & \multicolumn{8}{|c|}{ Experimento 1} \\
\hline E1PDR & 5,3 & 2,5 & 7,4 & 1,8 & 0,16 & 3,0 & 82 & $1.482 \mathrm{a}$ \\
\hline \multirow[t]{2}{*}{ E1C } & 5,3 & 2,7 & 8,7 & 2,2 & 0,15 & 3,0 & 74 & $802 a$ \\
\hline & \multicolumn{8}{|c|}{ Experimento 2} \\
\hline E2PD & 6,3 & 6,4 & 12,3 & 3,8 & 0,36 & 7,6 & 87 & $3.455 \mathrm{a}$ \\
\hline \multirow[t]{2}{*}{ E2C } & 5,6 & 4,8 & 12,9 & 4,0 & 0,18 & 5,3 & 83 & $1.207 \mathrm{~b}$ \\
\hline & \multicolumn{8}{|c|}{ Experimento 3} \\
\hline E3PD & 5,4 & 5,6 & 15,1 & 5,4 & 0,54 & 3,0 & 88 & $5.659 \mathrm{a}$ \\
\hline E3PDR & 5,6 & 7,3 & 21,5 & 1,3 & 0,45 & 4,5 & 88 & $1.808 \mathrm{~b}$ \\
\hline $\mathrm{E} 3 \mathrm{C}$ & 5,8 & 7,5 & 19,4 & 6,1 & 0,29 & 7,6 & 89 & $410 \mathrm{c}$ \\
\hline
\end{tabular}

${ }^{(1)}$ Médias seguidas de letras iguais, no mesmo experimento, não diferem entre si pelo teste de Tukey, a 5\% de probabilidade. E1PDR, sistema plantio direto, após nivelamento do terreno; E1C, sistema convencional com duas gradagens a 0,0-0,07 m, após nivelamento do terreno, após sete anos de pousio do cultivo de arroz e com semeadura de azevém no inverno e pastejo animal; E2PD, sistema plantio direto após campo nativo; E2C, sistema convencional após campo nativo; E3PD, sistema plantio direto; E3PDR, sistema plantio direto, após nivelamento do terreno com remaplan; E3C, sistema convencional, após cultivo de arroz irrigado em sistema convencional durante um ano sob campo nativo. 
A densidade máxima do solo (Ds referência) foi determinada pelo teste de Proctor normal com reuso de material (Nogueira, 1998), em amostras deformadas de solo, coletadas na camada de $0,0-0,10 \mathrm{~m}$. A Ds relativa (Dsr) foi obtida pela divisão da Ds atual pela Ds máxima.

No florescimento do arroz, foi avaliada a produção de massa de matéria seca em $2 \mathrm{~m}$ de linha. Na colheita, foram avaliados o número de panículas e a produtividade de grãos em área de $2 \mathrm{~m}^{2}$ por parcela.

Os resultados foram submetidos à análise de variância e, quando significativos, foi aplicado o teste de Tukey, a $5 \%$ de probabilidade, para comparação das médias entre os sistemas de manejo, em cada experimento.

\section{Resultados e Discussão}

O diâmetro médio geométrico (DMG) dos agregados apresentou valor elevado em comparação a solos cultivados com culturas de sequeiro (Tabela 2). O menor

Tabela 2. Diâmetro médio geométrico dos agregados (DMG), densidade do solo relativa (Dsr), densidade do solo (Ds), macroporosidade (Ma), microporosidade (Mi) e porosidade total $(\mathrm{Pt})$, em três experimentos e sistemas de manejo ${ }^{(1)}$.

\begin{tabular}{|c|c|c|c|c|c|c|}
\hline \multirow[t]{2}{*}{ Tratamento } & \multirow{2}{*}{$\begin{array}{l}\text { DMG } \\
(\mathrm{mm})\end{array}$} & Dsr & Ds & $\mathrm{Ma}$ & Mi & $\mathrm{Pt}$ \\
\hline & & \multicolumn{2}{|c|}{----- $\left(\mathrm{Mg} \mathrm{m}^{-3}\right)$----- } & \multicolumn{3}{|c|}{ - } \\
\hline & \multicolumn{6}{|c|}{$0,0-0,05 \mathrm{~m}$} \\
\hline E1PDR & $4,62 \mathrm{a}$ & 0,64 & $1,18 \mathrm{a}$ & $0,15 \mathrm{a}$ & $0,32 \mathrm{a}$ & $0,47 \mathrm{a}$ \\
\hline E1C & $4,54 \mathrm{a}$ & 0,64 & $1,17 \mathrm{a}$ & $0,15 \mathrm{a}$ & $0,29 b$ & $0,44 a$ \\
\hline E2PD & $5,25 \mathrm{a}$ & 0,59 & $0,99 \mathrm{a}$ & $0,16 \mathrm{~b}$ & $0,37 \mathrm{a}$ & $0,53 \mathrm{a}$ \\
\hline E2C & $4,79 \mathrm{~b}$ & 0,45 & $0,76 \mathrm{~b}$ & $0,26 \mathrm{a}$ & $0,27 b$ & $0,53 \mathrm{a}$ \\
\hline E3PD & $4,65 \mathrm{a}$ & 0,58 & $0,95 \mathrm{a}$ & $0,11 \mathrm{c}$ & $0,45 \mathrm{a}$ & $0,56 \mathrm{~b}$ \\
\hline E3PDR & $4,79 \mathrm{a}$ & 0,56 & $0,91 \mathrm{a}$ & $0,16 b$ & $0,39 b$ & $0,55 \mathrm{~b}$ \\
\hline \multirow[t]{2}{*}{$\mathrm{E} 3 \mathrm{C}$} & $4,88 \mathrm{a}$ & 0,50 & $0,81 \mathrm{~b}$ & $0,20 \mathrm{a}$ & $0,40 \mathrm{~b}$ & $0,60 \mathrm{a}$ \\
\hline & \multicolumn{6}{|c|}{$0,07-0,10 \mathrm{~m}$} \\
\hline E1PDR & - & 0,84 & $1,54 \mathrm{a}$ & $0,03 \mathrm{~b}$ & $0,28 \mathrm{a}$ & $0,31 \mathrm{a}$ \\
\hline E1C & - & 0,83 & $1,52 \mathrm{a}$ & $0,05 \mathrm{a}$ & $0,26 \mathrm{a}$ & $0,31 \mathrm{a}$ \\
\hline E2PD & - & 0,70 & $1,18 \mathrm{~b}$ & $0,08 \mathrm{a}$ & $0,36 \mathrm{a}$ & $0,44 a$ \\
\hline $\mathrm{E} 2 \mathrm{C}$ & - & 0,75 & $1,26 \mathrm{a}$ & $0,12 \mathrm{a}$ & $0,33 \mathrm{a}$ & $0,45 \mathrm{a}$ \\
\hline E3PD & - & 0,67 & $1,10 \mathrm{a}$ & $0,11 \mathrm{a}$ & $0,42 \mathrm{a}$ & $0,53 \mathrm{a}$ \\
\hline E3PDR & - & 0,67 & $1,10 \mathrm{a}$ & $0,07 \mathrm{~b}$ & $0,42 \mathrm{a}$ & $0,49 \mathrm{a}$ \\
\hline E3C & - & 0,67 & $1,09 \mathrm{a}$ & $0,07 \mathrm{~b}$ & $0,43 \mathrm{a}$ & $0,50 \mathrm{a}$ \\
\hline
\end{tabular}

${ }^{(1)}$ Médias seguidas de letras iguais, no mesmo experimento, não diferem entre si, pelo teste de Tukey, a 5\% de probabilidade. E1PDR, sistema plantio direto, após nivelamento do terreno; E1C, sistema convencional com duas gradagens a 0,0-0,07 $\mathrm{m}$ após nivelamento do terreno, após sete anos de pousio do cultivo de arroz e com semeadura de azevém no inverno e pastejo animal; E2PD, sistema plantio direto após campo nativo; E2C, sistema convencional após campo nativo; E3PD, sistema plantio direto; E3PDR, sistema plantio direto após nivelamento do terreno com remaplan; E3C, sistema convencional, após cultivo de arroz irrigado em sistema convencional, durante um ano sob campo nativo. - Não determinado. valor de DMG foi de 4,54 mm, no sistema de manejo convencional, superior ao de $2,81 \mathrm{~mm}$ encontrado por Souza Neto et al. (2008) em PD, com utilização de plantas de cobertura durante nove anos, em Latossolo Vermelho, argiloso, na camada $0,0-0,05 \mathrm{~m}$. Wendling et al. (2005), em Latossolo Vermelho de textura média, em PD e mata nativa, obtiveram DMG dos agregados valor inferior a 2,24 $\mathrm{mm}$ na camada de $0,0-0,05 \mathrm{~m}$.

O elevado valor do DMG dos agregados no solo estudado está relacionado aos maiores teores de matéria orgânica, superiores a $25 \mathrm{~g} \mathrm{~kg}^{-1}$, que melhoram a agregação do solo. Wohlenberg et al. (2004) verificaram que a estabilização dos agregados de um Argissolo Vermelho-Amarelo, de textura franco-arenosa, estava predominantemente relacionado ao teor de matéria orgânica. À medida que este diminui, principalmente pelo preparo excessivo do solo ou baixo aporte de material orgânico pelos sistemas de cultivo, decresce a estabilidade dos agregados.

Além do efeito da matéria orgânica, a mineralogia da fração argila do tipo 2:1 também proporciona maior estabilidade aos agregados. No solo estudado, a mineralogiaécompostapredominantementeporminerais 2:1, grupo das esmectitas (Pedron, 2007), que confere elevada coesão e agregação do solo, em comparação a solos com predomínio de caulinita na fração argila (Oliveira, 2005). Pedron (2007) verificou que os Neossolos Litólicos da região de Itaqui, derivados de rochas vulcânicas (basalto), apresentavam na mineralogia da fração argila a predominância de minerais $2: 1$, com destaque para as esmectitas, também verificado pelo índice ki superior a 2,2, que indica quantidade significativa de minerais $2: 1$.

Os sistemas de manejo diferiram apenas no experimento 2, em que o E2PD teve DMG superior ao E2C. No E2PD, sistema plantio direto em área de campo nativo, a maior estabilidade de agregados ocorreu em razão do não revolvimento do solo e, segundo Silva \& Mielniczuk (1997), da alta densidade de raízes das gramíneas perenes, da periódica renovação do sistema radicular e da liberação de exsudados pelas raízes que estimulam a atividade microbiana e a agregação em área de pastagem. No entanto, o E2C teve DMG de 4,79 mm, semelhante aos demais sistemas de manejo convencional e plantio direto, em áreas que já estavam sendo utilizadas para fins agrícolas (experimentos 1 e 3), o que indica que este solo tem alta estabilidade de agregados, e que o sistema de manejo convencional não reduz a estabilidade de agregados em comparação ao sistema plantio direto. 
A densidade do solo máxima (referência), determinada pelo teste de Proctor, foi de 1,84, 1,69 e 1,63 $\mathrm{g} \mathrm{cm}^{-3}$, respectivamente aos experimentos 1, 2 e 3 (Figura 1). A densidade do solo máxima diminuiu à medida que aumentou o conteúdo de argila, do experimento 1 para o 3, e o mesmo fato ocorreu com a densidade do solo no campo, o que indica uma relação inversa entre o conteúdo de argila e a densidade do solo. A densidade relativa do solo, que consiste na divisão da densidade atual pela densidade máxima, foi igual ou inferior a
0,64 , na camada de $0,0-0,05 \mathrm{~m}$, e igual ou inferior a 0,84 na de $0,07-0,10 \mathrm{~m}$, nos três experimentos e sistemas de manejo, o que indica níveis aceitáveis de compactação, quando considerados valores de Dsr limitantes para culturas de sequeiro. Segundo Arvidsson \& Håkansson (1991), na Dsr de 0,86, são obtidas as maiores produtividades que, em geral, decrescem em valores superiores, oscilam com as condições climáticas e culturas de sequeiro e apresentam resultados similares nos diferentes tipos de solos. Resultados semelhantes
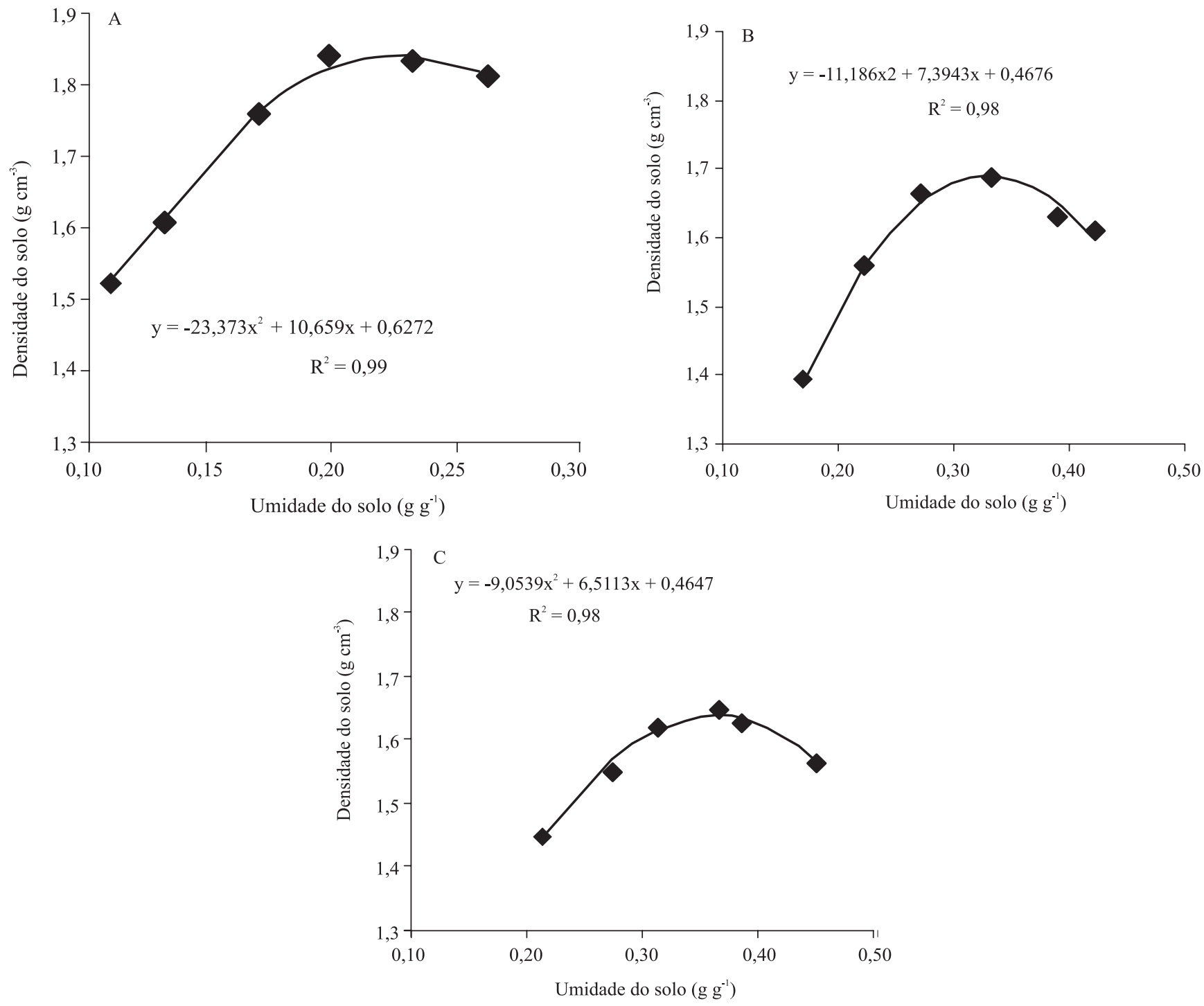

Figura 1. Densidade do solo em função da umidade gravimétrica, determinada pelo teste de Proctor, nos três experimentos: E1PDR, sistema plantio direto, após nivelamento do terreno; E1C, sistema convencional com duas gradagens a $0,0-0,07$ $\mathrm{m}$, após nivelamento do terreno, após sete anos de pousio do cultivo de arroz e com semeadura de azevém no inverno e pastejo animal (A); E2PD, sistema plantio direto após campo nativo; E2C, sistema convencional após campo nativo (B); E3PD, sistema plantio direto; E3PDR, sistema plantio direto após nivelamento do terreno com remaplan; E3C, sistema convencional após cultivo de arroz irrigado em sistema convencional, durante um ano sob campo nativo (C). 
foram encontrados por Beutler et al. (2005), para a cultura da soja, em que a máxima produtividade foi obtida na Dsr de 0,80 .

A densidade do solo foi inferior na camada de 0,0-0,05 m, no sistema convencional, nos experimentos 2 e 3 , em razão da descompactação pelo revolvimento do solo com as gradagens que atuaram até aproximadamente $0,07 \mathrm{~m}$ de profundidade. Entretanto, os valores de densidade do solo, no sistema plantio direto, são considerados baixos em relação aos valores limitantes para culturas de sequeiro (Beutler et al., 2005). No experimento 1, não ocorreram diferenças na densidade do solo entre os sistemas de manejo, possivelmente em razão de a ação da plaina niveladora ter sido mais intensa, o que promoveu a descompactação superficial do solo. $\mathrm{Na}$ camada de 0,07-0,10 m ocorreram poucas diferenças na densidade do solo entre os sistemas de manejo, em razão do não revolvimento do solo nessa camada mais profunda. No entanto, ressalta-se a maior densidade relativa do solo e a maior densidade do solo no campo no experimento 1 e nos dois sistemas de manejo, na camada de 0,07-0,10 m, o que indica degradação pela compactação em comparação aos experimentos 2 e 3 . Essa compactação ocorreu pelo não revolvimento do solo nessa camada e pelo cultivo de arroz durante vários anos, quando ocorreu o tráfego de máquinas na superfície e, consequentemente compactação que resultou em menor macroposoridade e porosidade total do solo (Tabela 2).

$\mathrm{O}$ solo nos experimentos apresentou altos teores de matéria orgânica e saturação por bases, que é um solo com fertilidade adequada, o que contribuiu para o desenvolvimento e alta produtividade do arroz irrigado. $\mathrm{O}$ número de panículas não diferiu entre os sistemas de manejo, nos três experimentos (Tabela 3). A massa de matéria seca do arroz, determinada no florescimento, divergiu entre os sistemas de manejo apenas no experimento 3 e foi menor no E3PDR em comparação ao $\mathrm{E} 3 \mathrm{C}$, que não diferiram do E3PD. A produtividade também divergiu entre os sistemas de manejo apenas no experimento 3, e foi superior no E3C em comparação ao E3PDR e ao E3PD.

A menor produtividade do arroz no E3PD e E3PDR, no experimento 3, pode ser consequência da alta quantidade de resíduos culturais do arroz cultivado no ano anterior, que atingiu valores de $5.689 \mathrm{~kg} \mathrm{ha}^{-1}$ na superfície do solo, no E3PD, o que pode ter prejudicado o desenvolvimento e a produtividade da cultura. No sistema convencional, os restos culturais foram incorporados ao solo por meio de duas gradagens e permaneceram mais de um mês nessas condições para sua decomposição, antes da semeadura, e mais um mês após a semeadura até ser realizada a inundação do solo, fato que pode ter reduzido a produção de ácidos orgânicos prejudiciais ao arroz, na comparação ao sistema plantio direto. Segundo Pereira et al. (2005), 2 a 3 Mg de massa de matéria seca são suficientes para que se tenha uma adequada cobertura para implantação do PD, em solos de várzea, pois quantidades maiores, além de dificultar a evaporação da água do solo, podem produzir ácidos orgânicos em níveis tóxicos ao arroz.

Camargo et al. (2001) fizeram uma revisão sobre o efeito de materiais orgânicos, entre os quais a palha de arroz, em condições alagadas e decomposição anaeróbica, na produção de ácidos orgânicos voláteis e seus efeitos na produtividade do arroz irrigado. Esses autores verificaram os efeitos nocivos de acidos orgânicos voláteis, quando em excesso, na absorção de nutrientes, perfilhamento, produção de massa de matéria seca, número de panículas, esterilidade de flores e produtividade do arroz. Camargo et al. (1995) verificaram que quantidades excessivas de palha de arroz, acima de 6,5 $\mathrm{Mg} \mathrm{ha}^{-1}$ incorporado ao solo, em

Tabela 3. Número de panículas, massa de matéria seca (MS) da parte aérea e produtividade do arroz irrigado, em três experimentos e sistemas de manejo ${ }^{(1)}$.

\begin{tabular}{lccc}
\hline Tratamento & $\begin{array}{c}\text { Número de panículas } \\
\text { por } \mathrm{m}^{2}\end{array}$ & $\begin{array}{c}\text { MS parte aérea } \\
\left(\mathrm{kg} \mathrm{ha}^{-1}\right)\end{array}$ & $\begin{array}{c}\text { Produtividade } \\
\left(\mathrm{kg} \mathrm{ha}^{-1}\right)\end{array}$ \\
\hline E1PDR & $442 \mathrm{a}$ & $\begin{array}{c}\text { Experimento } 1 \\
6.980 \mathrm{a}\end{array}$ & $7.679 \mathrm{a}$ \\
E1C & $7.895 \mathrm{a}$ & $8.047 \mathrm{a}$ \\
\hline & $475 \mathrm{a}$ & Experimento 2 \\
E2PD & $563 \mathrm{a}$ & $9.106 \mathrm{a}$ & $10.442 \mathrm{a}$ \\
E2C & $563 \mathrm{a}$ & $8.035 \mathrm{a}$ & $10.095 \mathrm{a}$ \\
\hline & & Experimento 3 & \\
E3PD & $506 \mathrm{a}$ & $10.143 \mathrm{ab}$ & $10.103 \mathrm{~b}$ \\
E3PDR & $486 \mathrm{a}$ & $9.131 \mathrm{~b}$ & $10.170 \mathrm{~b}$ \\
E3C & $496 \mathrm{a}$ & $11.542 \mathrm{a}$ & $11.174 \mathrm{a}$ \\
\hline
\end{tabular}

${ }^{(1)}$ Médias seguidas de letras iguais, no mesmo experimento, não diferem entre si pelo teste de Tukey, a 5\% de probabilidade. E1PDR, sistema plantio direto, após nivelamento do terreno; E1C, sistema convencional com duas gradagens a 0,0-0,07 m, após nivelamento do terreno, após sete anos de pousio do cultivo de arroz e com semeadura de azevém no inverno e pastejo animal; E2PD, sistema plantio direto após campo nativo; E2C, sistema convencional após campo nativo; E3PD, sistema plantio direto; E3PDR, sistema plantio direto após nivelamento do terreno com remaplan; E3C, sistema convencional após cultivo de arroz irrigado em sistema convencional, durante um ano sob campo nativo. 
experimento de vasos, reduziram a produtividade de arroz irrigado. Segundo Johnson et al. (2006), em sistema plantio direto e cultivo mínimo de arroz irrigado, em que os resíduos vegetais permanecem na superfície do solo, ocorre maior produção de ácidos orgânicos que limitam o crescimento $\mathrm{e}$ a produtividade das plantas, em casos de altas concentrações. Os principais ácidos orgânicos produzidos por microrganismos anaeróbios, por meio da fermentação da matéria orgânica do solo, são o acético, propiônico e o butírico; o primeiro em maior quantidade é liberado nas primeiras semanas após a inundação (Angeles et al., 2005).

No experimento 1, obteve-se menor produtividade, em razão de a cultivar Puitá Inta CL ser menos produtiva, em comparação à Irga 424, utilizada nos experimentos 2 e 3 .

$\mathrm{O}$ PD, além de evitar o revolvimento do solo e diminuir os custos de produção, permite aos produtores o uso mais eficiente das máquinas agrícolas e o plantio na época recomendada para a cultura, o que proporciona produtividade do arroz irrigado semelhante à do sistema convencional, exceto no caso de palha excessiva sobre o solo, fato que ainda necessita mais estudos. Isto é importante uma vez que a época de semeadura ideal é de poucas semanas e, muitas vezes, ocorrem intensas precipitações nesses períodos, o que diminui drasticamente a quantidade de dias ideais disponíveis à semeadura.

\section{Conclusões}

1. No sistema plantio direto, as propriedades físicas do solo não diferem das do sistema convencional com gradagens em sistema de produção de arroz irrigado por inundação.

2. O cultivo continuado com arroz irrigado por inundação causa compactação do solo na camada de $0,07-0,10 \mathrm{~m}$ de profundidade, no sistema plantio direto e no sistema convencional.

3. Na presença de adequada quantidade de restos culturais, a produtividade do arroz irrigado é semelhante nos sistemas plantio direto e convencional de preparo do solo.

\section{Agradecimentos}

Ao Técnico Agrícola da fazenda Fonte Rica, Geri Munareto, pelo auxílio na execução do experimento.

\section{Referências}

ANDRES, A.; ÁVILA, L.A. de; MARCHEZAN, E.; MENEZES, V.G. Rotação de culturas e pousio do solo na redução do banco de sementes de arroz-vermelho em solo de várzea. Revista Brasileira de Agrociência, v.7, p.85-88, 2001.

ANGELES, O.R.; JOHNSON, S.E.; BURESH, R.J. Soil solution sampling for organic acids in rice paddy soils. Soil Science Society of America Journal, v.70, p.48-70, 2005.

ARVIDSSON, J.; HÅKANSSON, I. A model for estimating crop yield losses caused by soil compaction. Soil \& Tillage Research, v.20, p.319-332, 1991.

BEUTLER, A.N.; CENTURION, J.F.; ROQUE, C.G.; FERRAZ, M.V. Densidade relativa ótima de Latossolos Vermelhos para a produtividade de soja. Revista Brasileira de Ciência do Solo, v.29, p.843-849, 2005.

CAMARGO, F.A. de O; SANTOS, G. de A.; ROSSIELLO, R.O.P.; ZONTA, E. Incorporação de palha de arroz em um Gleissolo e efeitos no rendimento da cultura do arroz irrigado. Pesquisa Agropecuária Brasileira, v.30, p.983-987, 1995.

CAMARGO, F.A. de O.; ZONTA, E.; SANTOS, G. de A.; ROSSIELLO, R.O.P. Aspectos fisiológicos e caracterização da toxidez de ácidos orgânicos voláteis em plantas. Ciência Rural, v.31, p.523-529, 2001

CLAESSEN, M.E.C. (Org.) Manual de métodos de análise de solo. 2.ed. Rio de Janeiro: Embrapa- CNPS, 1997. 212p.

JOHNSON, S.E.; ANGELES, O.R.; BRAR, D.S.; BURESH, R.J. Faster anaerobic decomposition of a brittle straw rice mutant: implications for residue management. Soil Biology \& Biochemistry, v.38, p.1880-1892, 2006.

NOGUEIRA, J.B. Mecânica de solos: ensaios de laboratório. São Carlos: USP, 1998. 248p.

OLIVEIRA, J.B. Pedologia aplicada. 2.ed. Piracicaba: FEALQ, 2005. 574p.

PAULETO, E.A.; GOMES, A.S.; FRANZ, A.F.H.; SOUZA, R.O. Manejo de solo e água em arroz irrigado. In: PESKE, S.; NEDEL, J.; BARROS, A. (Ed.) Produção de sementes de arroz. Pelotas: UFPel, 1993. p.64-144.

PEDRON, F. de A. Mineralogia, morfologia e classificação de saprólitos e Neossolos derivados de rochas vulcânicas no Rio Grande do Sul. 2007. 160p. Tese (Doutorado) - Universidade Federal de Santa Maria, Santa Maria.

PEDROTTI, A.; PAULETTO, E.A.; GOMES, A. da S.; TURATTI, A.L.; CRESTANA, S. Sistemas de cultivo de arroz irrigado e a compactação de um Planossolo. Pesquisa Agropecuária Brasileira, v.36, p.709-715, 2001.

PEREIRA, D.P.; BANDEIRA, D.L.; QUINCOZES, E. da R.F. (Ed.). Cultivo do arroz irrigado no Brasil. 2005. Disponível em: <http://sistemasdeproducao.cnptia.embrapa.br/FontesHTML/ Arroz/ArrozIrrigadoBrasil>. Acesso em: 21 jun. 2010.

SANTOS, H.G. dos; JACOMINE, P.K.T.; ANJOS, L.H.C. dos; OLIVEIRA, V.A. de; OLIVEIRA, J.B. de; COELHO, M.R.; LUMBRERAS, J.F.; CUNHA, T.J.F. (Ed.). Sistema brasileiro de 
classificação de solos. 2.ed. Rio de Janeiro: Embrapa Solos, 2006. $306 \mathrm{p}$.

SILVA, I.F.; MIELNICZUK, J. Avaliação do estado de agregação do solo afetado pelo uso agrícola. Revista Brasileira de Ciência do Solo, v.21, p.313-319, 1997.

SOCIEDADE BRASILEIRA DE CIÊNCIA DO SOLO. Comissão de Química e Fertilidade do Solo. Manual de recomendações de adubação e calagem para os estados do Rio Grande do Sul e Santa Catarina. 10.ed. Porto Alegre: Sociedade Brasileira de Ciência do Solo - Núcleo Regional Sul, 2004. 394p.

SOCIEDADE SUL-BRASILEIRA DE ARROZ IRRIGADO. Arroz irrigado: recomendações técnicas da pesquisa para o Sul do Brasil. Porto Alegre: Palotti, 2010. 188p.

SOUSA NETO, E.L. de; ANDRIOLI, I.; BEUTLER, A.N.; CENTURION, J.F. Atributos físicos do solo e produtividade de milho em resposta a culturas de pré-safra. Pesquisa Agropecuária Brasileira, v.43, p.255-260, 2008.

STRECK, E.V.; KÄMPF, N.; DALMOLIN, R.S.D.; KLAMT, E.; NASCIMENTO, P.C. do; SCHNEIDER, P.; GIASSON, E.; PINTO, L.F.S. Solos do Rio Grande do Sul. 2.ed. Porto Alegre: Associação Riograndense de Empreendimentos de Assistência Técnica e Extensão Rural, 2008. 222p.

WENDLING, B.; JUCKSCH, I.; MENDONÇA, E. de S.; NEVES, J.C.L. Carbono orgânico e estabilidade de agregados de um Latossolo Vermelho sob diferentes manejos. Pesquisa Agropecuária Brasileira, v.40, p.487-494, 2005.

WOHLENBERG, E.V.; REICHERT, J.M.; REINERT, D.J.; BLUME, E. Dinâmica da agregação de um solo franco-arenoso em cinco sistemas de culturas em rotação e em sucessão. Revista Brasileira de Ciência do Solo, v.28, p.891-900, 2004.

Recebido em 3 de agosto de 2010 e aprovado em 4 de novembro de 2010 